\title{
A MISSÃO DE ROCKEFELLER: AS RELAÇÕES DE UM MILIONÁRIO-MISSIONÁRIO COM O BRASIL
}

\section{ROCKEFELLER'S MISSION: THE RELATIONS OF A MILLIONAIRE-MISSIONARY WITH BRAZIL}

\author{
Celso Fernando Claro de Oliveira*
}

TOTA, Pedro Antonio. O amigo americano: Nelson Rockefeller e o Brasil. São Paulo: Companhia das Letras, 2014.

\footnotetext{
*Mestre em História pela Universidade Estadual de Maringá, Doutorando em História pela Universidade Federal de Santa Catarina, Florianópolis, Santa Catarina, Brasila. Foi bolsista sanduíche na Yale University (2014/2015)

E-mail: celsooliveira88@gmail.com
} 
Publicado no ano 2000 pela Companhia das Letras, "O imperialismo sedutor: A americanização do Brasil na época da Segunda Guerra" se tornou uma referência para os estudos sobre as relações Brasil-Estados Unidos na primeira metade da década de 1940. Na obra, o historiador Pedro Antonio Tota, professor da Pontifícia Universidade Católica de São Paulo (PUCSP), analisa o papel do Office of the Coordinator of Inter-American Affairs (OCIAA) - agência governamental estadunidense criada com o objetivo de fomentar a Política de Boa Vizinhança - no Brasil. Segundo o autor, o órgão foi uma verdadeira "fábrica de ideologias", utilizando-se de projetos de naturezas diversas (econômica, educacional, artística, etc) e de um forte investimento em propaganda a partir dos meios de comunicação para popularizar o American way of life. Isso desencadeou um processo de mudanças comportamentais na sociedade brasileira e contribuiu para expandir a hegemonia estadunidense sobre o país, levando à "americanização" mencionada no subtítulo do livro". Passada quase uma quinzena desde essa publicação, Tota revisita a trajetória do líder do OCIAA em "O amigo americano: Nelson Rockefeller e o Brasil", lançado em 2014 pela mesma editora.

Dividida em sete capítulos, além de um prólogo e um epílogo, a obra tem por objetivo analisar como se originou e se desenvolveu o interesse de Nelson Rockefeller pelo Brasil entre 1937 e 1969 considerando as mudanças na dinâmica das relações Brasil-Estados Unidos e os interesses pessoais do empresário ao longo dessa trajetória - em especial, seu candente anticomunismo. Talvez o ponto de maior destaque do trabalho seja a habilidade de Tota analisar a personalidade de seu "objeto de estudo" tomando uma posição crítica sem demonizá-lo. Assim, Rockefeller emerge como um personagem sui generis e ambíguo. Nascido em "berço de ouro", foi criado em um ambiente de forte tradição religiosa, educado para compreender o valor da parcimônia e da filantropia. Considerado um aluno pouco brilhante, multiplicou a fortuna de sua família e se tornou um político influente. Filiado ao Partido Republicano, era considerado demasiado "liberal" por muitos de seus correligionários ${ }^{2}$. Todavia, o "paradoxo" mais relevante para o trabalho de Tota era o de Rockefeller se considerar responsável por salvar as pessoas da pobreza desde que isso preservasse as estruturas sociais existentes e continuasse a garantir a lucratividade de seus negócios. Seu foco era a América Latina, sendo que, para o Brasil, ele havia estabelecido "um grande projeto econômico, político e social destinado a manter o país a salvo das tentações socialistas, comunistas e mesmo nacionalistas"3. Para o autor, é a partir dessa "missão" que se deve compreender como se delineia o interesse do milionário pelo país.

O novo trabalho de Tota tem potencial para se tornar uma referência, pois apesar de o relacionamento de Nelson Rockefeller com o Brasil durante a Segunda Guerra Mundial já ter rendido importantes produções nacionais 
e internacionais e continuar a atrair a atenção de pesquisadores em diversos níveis, os projetos anticomunistas desenvolvidos aqui pelo milionário estadunidense durante a Guerra Fria ainda recebem pouca atenção dos autores brasileiros. Nesse sentido, o historiador faz uma importante contribuição que pode fomentar novas incursões nesse campo, além de dialogar com alguns dos mais relevantes estudos já desenvolvidos nos Estados Unidos sobre o assunto, como a premiada contribuição de Elizabeth Anne Cobbs ${ }^{4}$. Entretanto, ao buscar transitar entre o público acadêmico e o não-acadêmico, Tota emprega uma estrutura de escrita que foge dos padrões científicos. Essa conjuntura textual torna a leitura agradável, porém, prejudica a análise do amplo leque de fontes e a realização de debates teóricos, de modo que o leitor acadêmico pode considerar que muitas das questões presentes na obra não são abordadas satisfatoriamente apesar do esforço do autor em realizar avaliações minuciosas.

Dono de uma escrita fluída, acessível e levemente irônica, o autor peca ao se utilizar excessivamente de "histórias curiosas" sobre Rockefeller ao longo do livro. Embora alguns dos relatos sejam interessantes e contribuam para complementar os debates realizados por Tota, muitos se afastam do objetivo central e, por vezes, engessam a leitura. O exemplo mais notável é o prólogo, em que a apresentação do conteúdo do material é pouquíssimo desenvolvida enquanto o historiador narra, de maneira bastante detalhada, um acontecimento de relevância reduzida considerando-se o escopo de seu trabalho; que só é retomado e concluído no terceiro capítulo, mais de 100 páginas adiante. No primeiro capítulo, "A formação de um predestinado", um problema semelhante ocorre: Tota faz longas digressões sobre a história do avô do empresário, John D. Rockefeller, e sobre as origens da fortuna familiar, passagens que poderiam ter sido trabalhadas de forma mais sucinta. Outro fator incômodo e que se repete no decorrer da produção é o uso meramente ilustrativo de fotografias e outros recursos imagéticos, excetuando-se algumas raras tentativas de análise mais aprofundada.

É a partir do subcapítulo "Nascimento, infância e juventude de Nelson Rockefeller" que a obra ganha fôlego. De forma problematizada, Tota debate como a educação familiar - mesclando rígidos preceitos da religiosidade puritana e preservação do status quo com a valorização de uma "vida comum" e da convivência com pessoas de diferentes etnias e classes sociais - contribuiu para que o empresário formulasse sua futura "missão" para com os mais pobres. Segundo o autor, os pais de Nelson Rockefeller inauguram uma geração mais liberal dentro da família, preocupada em desvincular seus negócios do capitalismo desregrado que então imperava nos Estados Unidos. Tota tem o cuidado de pontuar que tal interesse não era altruísta: investir em uma relação harmônica com os empregados e em melhorias das condições de trabalho visava a conter o avanço dos ideários de esquerda no país ao início do 
século XX. Esse pensamento viria a ocupar um espaço central nos projetos de Rockefeller para a América Latina ao longo de sua vida. Outro elemento-chave do primeiro capítulo é a análise do autor sobre a personalidade do empresário, destacando como sua facilidade de comunicação, espírito gregário e apreço pelas artes ajudaram-no a galgar posições e estabelecer contatos, vindo a se aproximar do governo democrata de Franklin Roosevelt durante o New Deal.

Em "A descoberta do Brasil", segundo capítulo da obra, Tota dedicase a estudar a primeira viagem de Rockefeller ao "gigante do sul" em 1937. Recorrendo à documentação do arquivo da família, o historiador aborda minuciosamente a preparação, o andamento e os resultados da empreitada. $\mathrm{O}$ capítulo é bastante informativo e bem fundamentado, recorrendo ao uso de relatórios burocráticos e correspondências pessoais para avaliar as impressões do jovem milionário sobre o Brasil, buscando encontrar as origens de seu interesses empresariais e missionários no país. Todavia, o autor por vezes gasta demasiado tempo discorrendo sobre detalhes supérfluos - como os acontecimentos que marcaram a viagem de avião de Rockefeller e sua comitiva - e faz uma análise demasiado irônica de um mapa caricato sobre a América Latina, perdendo uma boa oportunidade para debater a questão dos estereótipos perpetuados nos Estados Unidos sobre os vizinhos ao sul da fronteira. Um segundo ponto que poderia ter sido melhor problematizado é a questão da concorrência imperialista e ideológica entre Washington e Berlim sobre o Brasil à época: uma análise mais detalhada e um debate sobre os conceitos "imperialismo" e "ideologia" teriam enriquecido o trabalho.

$\mathrm{O}$ autor considera a viagem essencial para o futuro trabalho de Rockefeller junto ao governo Roosevelt. O boom desenvolvimentista encorajado pelo Estado Novo anima o empresário, que vê grandes oportunidades para a expansão dos negócios estadunidenses no país, contudo, reconhece a necessidade de neutralizar dois "obstáculos": os anseios nacionalistas brasileiros e a concorrência alemã - esta última cada vez mais ameaçadora devido à escalada de eventos que prenunciavam o início da Segunda Guerra Mundial e à simpatia que angariava entre alguns governos e camadas sociais das república latino-americanas. De acordo com o Tota, as experiências da viagem despertaram em Rockefeller o interesse de arquitetar uma aproximação mais efetiva entre os Estados Unidos e a América Latina, considerando a importância que a região viria a assumir em caso de um conflito. De volta aos Estados Unidos, o milionário criou um think tank para debater sobre o assunto e valeu-se de sua rede de contatos para levar tais ideias até Roosevelt. Em Washington, o temor provocado pela expansão da influência comercial e ideológica da Alemanha no continente tornava-se alarmante. Interessado em mobilizar um bloco de defesa hemisférica, o presidente criou o já mencionado OCIAA, convidando o republicano moderado para assumir o órgão e determinar seus meios de atuação. 
O terceiro capítulo, "A redescoberta do Brasil", trabalha os projetos de Rockefeller para o país durante a Segunda Guerra Mundial. Merecem destaque os subcapítulos "O homem de Roosevelt no Brasil" e "O American way of life como modelo para os brasileiros"; em que a agenda do milionário é esmiuçada de forma bastante detalhada. Tota analisa o papel de Rockefeller como um representante do governo estadunidense no Brasil, responsável por divulgar uma imagem positiva de seu país e fomentar as boas relações entre os dois grandes vizinhos americanos. Tomando parte nas celebrações da Semana da Pátria, ele esteve em diversos eventos oficiais ao lado de Vargas e seus ministros, discursando sobre as supostas semelhanças entre o desenvolvimentismo de ambas as nações e o futuro grandioso que aguardava o Brasil após sua valorosa contribuição no esforço de guerra. Sempre buscando ampliar sua rede de contatos, o empresário atuou de modo a manter o público brasileiro aberto para receber os valores do American way of life, o que era importante não apenas para a vitória no conflito, mas também para garantir a primazia comercial e ideológica estadunidense na região.

Posteriormente, Tota direciona sua atenção ao funcionamento e aos projetos do OCIAA no país, trabalhando as diversas frentes de atuação do órgão, em especial, as iniciativas para potencializar a produção de borracha na Amazônia e o que o autor denomina de uso da "cultura como arma [de guerra]"5, ou seja, a mobilização dos meios de comunicação para difundir o American way of life ao público brasileiro. Embora o texto mantenha sua qualidade narrativa e seja igualmente informativo, o autor reutiliza muitos dos exemplos e situações anteriormente analisados em "O imperialismo sedutor", além de não dedicar parte desses subcapítulos para debater alguns conceitos que aparecem como centrais para entender a atuação do OCIAA no Brasil; tais como "propaganda", "comunicação", "arte" e "cultura". Mesmo sendo mencionado, o conceito "soft power" aparece sem qualquer contextualização. Além disso, a conclusão ao prólogo, narrada no subcapítulo "Intriga internacional", aparece deslocada, reforçando a ideia de que foi inserida apenas a título de curiosidade.

A participação do Brasil na guerra não alçou o país à projeção esperada; e ao final do conflito as relações com os Estados Unidos esfriaram. Bem menos disposto a dialogar com os países latino-americanos do que seu antecessor, o presidente Harry S. Truman desmantelou a agência comandada por Rockefeller e o despediu. Todavia, isso não representou o fim do interesse do empresário pelo país latino-americano: no capítulo 4, "A salvação da lavoura (I): semeando o bem-estar", Tota se dedica a analisar de forma problematizada a roupagem que a "missão" de Rockefeller para com o Brasil adquiriu no mundo pós-guerra. Considerando que Washington vinha fazendo pouco para frear o avanço do comunismo no continente, o milionário reúne um grupo de aliados e funda a American International Association 
for Economic and Social Development (AIA) e o International Basic Economic Corporation (Ibec), instituições irmãs que visavam a fomentar o desenvolvimento econômico e a melhoria das condições de vida brasileiras. No entendimento de Rockefeller, a maneira mais eficaz de se derrotar a esquerda era apresentar o capitalismo como um sistema humanizado, em que todos teriam igual oportunidade de ascensão social - bastava um "pequeno empurrão" para que o Brasil alcançasse a "modernidade" sem recorrer às "perigosas" ideias de esquerda. O autor segue uma estrutura similar aos capítulos anteriores do livro, trabalhando de forma detalhada o processo de constituição das duas agências e sua divulgação em território brasileiro promovida, em partes, pelo próprio Rockefeller -; além de analisar alguns de seus projetos, dedicando atenção especial à Companhia Agrícola e Industrial de Bocaina e ao plano de melhoramentos para a cidade de São Paulo.

Tota continua a analisar as iniciativas da AIA e do Ibec no capítulo seguinte, "A salvação da lavoura (II): Anticomunismo e negócios", incluindo as pesquisas com milho híbrido desenvolvidas pela Agroceres e a criação da Associação de Crédito e Assistência Rural (Acar) em Minas Gerais, órgão que concedia não apenas crédito a pequenos agricultores, mas também orientações sobre saúde, educação e cuidados com a lavoura. Os programas empreendidos pelas agências-irmãs foram se diversificando e se espalhando pelo país, contando com o apoio das elites locais, ávidas pelo tão esperado "desenvolvimento"; muito embora nem todas as propostas tivessem sucesso ou fossem concretizadas. É importante ressaltar o debate que o autor conduz a respeito do anticomunismo arraigado na sociedade brasileira e difundido pelo empresariado, veículos de comunicação e diversas instituições; demonstrando o cuidado de não tornar Rockefeller o único incentivador da luta contra a esquerda no país apesar de sua crescente paranoia que fazia-o até mesmo se posicionar contra as negociações de paz entre Estados Unidos e União Soviética. Almejando realizar uma narrativa minuciosa das visitas do empresário ao Brasil nas décadas de 1940 e 1950, Tota novamente se vale do rico arquivo pessoal de seu personagem, explorando uma quantidade significativa de documentos, mas isso não evita que a escrita por vezes se torne enfadonha. Em alguns momentos, há a impressão de que algumas fontes são citadas por mera curiosidade.

A popularidade de Rockefeller entre os brasileiros era tamanha que gerou uma grande produção de cartas destinadas ao empresário. Tota dedica o sexto capítulo do livro, "Cartas a um milionário: um americano na terra do favor" a analisar algumas dessas missivas. Embora não haja uma metodologia clara que explique o processo de seleção dos materiais avaliados, o autor comprova que a imagem de Rockefeller no Brasil era bastante positiva, uma impressão difundida entre membros de diferentes classes sociais em várias regiões do país. Os emissários e os motivos das correspondências eram 
os mais diversos, incluindo convites de autoridades, notícias enviadas por amigos, cartas de agradecimento e uma série de pedidos inusitados - de quantias de dinheiro a autógrafos. As cartas não apenas permitem a Tota estudar o comportamento de Rockefeller com relação a seus interlocutores ou os procedimentos de triagem realizados por seus assessores, mas também fornecem importantes considerações sobre o zeitgeist presente nos textos; incluindo o medo da guerra nuclear, as fixações consumistas e o anticomunismo presentes na sociedade brasileira.

Tota reserva o último capítulo de sua obra para discutir o papel político das artes plásticas nos projetos de Rockefeller. Em "Arte e cultura: Receitas para a elite brasileira", o historiador explora os esforços do milionário para popularizar entre a alta sociedade do Brasil o gosto pelas artes moderna e abstrata; as quais acreditava ser representativas do desenvolvimentismo, das inovações e da liberdade individual capitalista em contraponto ao classicismo "conservador" e ao regrado realismo soviético. Embora seja um capítulo menos volumoso que os anteriores, é onde os debates sobre "arte", "(alta) cultura" e "imperialismo cultural" aparecem com maior força enquanto Tota recorre ao mesmo tom minucioso para analisar o envolvimento de Rockefeller com a criação museus nas cidades de Rio de Janeiro e São Paulo, bem como, sua contribuição para a organização da primeira Bienal paulista. Ainda que de modo reduzido, as críticas da imprensa de esquerda aos projetos do empresário estadunidense no Brasil também são abordadas pelo autor, fornecendo um interessante panorama do momento.

O epílogo da obra funciona como uma espécie de conclusão estendida, em que Tota retoma alguns dos pontos principais do trabalho para então avaliar o afastamento de Rockefeller do Brasil à medida em que os interesses do magnata se direcionavam cada vez mais ao governo do estado de Nova Iorque - cargo para o qual foi eleito em 1959 e reeleito duas vezes consecutivas - e às disputas para obter a nomeação do Partido Republicano à presidência dos Estados Unidos - objetivo que nunca alcançou apesar de ter se tornado vice de Gerald Ford após a renúncia de Richard Nixon. Ao narrar a última viagem do empresário ao Brasil, em 1969, o pesquisador adota um tom melancólico, destacando as diferenças entre a ditadura varguista (considerada "esclarecida" por Rockefeller) e a ditadura militar. Muitos dos amigos e conhecidos do empresário haviam falecido, se afastado ou sofriam com as perseguições políticas; a participação popular era mínima e os protestos contra sua presença no país - um deles, realizado no Largo da Batata em São Paulo, contou com a presença do próprio Tota - eram numerosos apesar de o regime militar ter se esforçado para proteger seu convidado e evitar uma publicidade negativa no estrangeiro. Apesar de seu incômodo visível com a ditadura, o anticomunismo de Rockefeller tornava-o complacente com o governo brasileiro. Mais uma vez, chama a atenção a escrita minuciosa que o 
autor emprega ao avaliar o momento.

Conforme destacamos anteriormente, "O amigo americano" tem potencial para se tornar um estudo de referência sobre as relações entre Nelson Rockefeller e o Brasil. Salientamos novamente as qualidades do material, como a escrita fluída e detalhada, o uso de uma vasta gama de fontes e a preocupação do autor em compreender a personalidade multifacetada do empresário/político/missionário que acreditava ter uma missão bastante peculiar para o futuro brasileiro. Ainda que sintamos falta de debates a respeito dos conceitos teórico-metodológico empregados por Tota e de uma melhor abordagem de certos documentos - em especial, as fotografias e demais recursos imagéticos - trata-se de uma leitura agradável que pode atrair diferentes públicos e incentivar novas pesquisas sobre o tema.

\section{NOTAS}

${ }^{1}$ Conferir: TOTA, Antonio Pedro. O imperialismo sedutor: A americanização do Brasil na época da Segunda Guerra. São Paulo: Companhia das Letras, 2000.

${ }^{2}$ Segundo Tota, o termo "liberal” nos Estados Unidos é utilizado para se referir aos partidários de reformas sociais e favoráveis à intervenção estatal para a realização das mesmas, uma postura pouco identificável com o Partido Republicano. TOTA, Pedro Antonio. O amigo americano: Nelson Rockefeller e o Brasil. São Paulo: Companhia das Letras, 2014, p.62.

${ }^{3}$ TOTA, 2014, p. 18.

${ }^{4}$ COBBS, Elizabeth Anne. The rich neighbor policy: Rockefeller and Kaiser in Brazil. New Haven: Yale University Press, 1992.

${ }^{5}$ TOTA, 2014, p. 131.

Artigo recebido em janeiro de 2015. Aceito em agosto de 2015. 